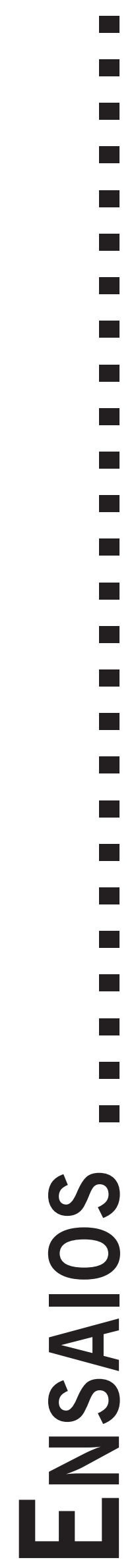




\title{
CARTA A UMA JOVEM PSICOTERAPEUTA
}

\author{
Letter to a Young Psychotherapist
}

Carta a una Joven Terapeuta

Celana Cardoso Andrade

\begin{abstract}
Resumo: O início da prática clínica na psicologia é vivido pela jovem terapeuta como um grande desafio. Envolve sentimentos de esperança, de medo, de incerteza, dentre outros. Esses sentimentos advêm da difícil tarefa de não pular etapas nesse processo, de ter paciência para obter formação teórica, metodológica e pessoal, e, ainda, de ir além da teoria estudada, em um espaço em que as respostas não são tão óbvias. Tornar-se terapeuta é um caminho solitário em que é preciso, também, buscar respostas em si mesma, tanto nos questionamentos que surgem em sua vida pessoal quanto nos relativos à profissão. A pessoa que escolhe ser terapeuta precisa entender que terapia é uma expressão que significa cuidado, tratamento e cura. Cuidar implica consideração, interesse, atenção, solicitude, zelo, preocupação, atitudes comuns nas terapeutas iniciantes em sua relação com os clientes, mas raras quando se referem a elas mesmas. Para tanto, a jovem terapeuta precisa estar disponível para o encontro, o contato, condição que se faz imprescindível na relação terapêutica e, ao mesmo tempo, ela deve cuidar de si própria. O objetivo dessa carta é, de alguma maneira, mostrar que a pessoa precisa começar a realizar atendimentos, mesmo que ainda não se sinta totalmente pronta para tal empreitada. A vontade e a disposição para atender, além de toda a teoria estudada, com certeza, a capacitará para iniciar essa atividade.
\end{abstract}

Palavras-chave: Terapia; Início Profissional; Suporte Teórico; Suporte Emocional.

Abstract: The onset of clinical practice in psychology is experienced by young therapist as a major challenge. It involves feelings of hope, fear and uncertainty, among others. These feelings stem from the difficult task of not skipping steps in the process, having patience for theoretical, methodological and personal, and also going beyond the theory studied in an area where answers are not so obvious. Becoming a therapist is a lonely path in which we must also seek answers in ourselves for the questions that arise in our personal lives and also in governing the profession. The person who chooses to be a therapist needs to understand that therapy is an expression that means care, treatment and cure. Caring involves consideration, interest, attention, and concern, common attitudes among therapists in their relationship with patients, but rare when referring to themselves. For this reason the young therapist must be available for the meeting and the contact, a condition which is indispensable in the therapeutic relationship and, at the same time, she should take care of herself. The purpose of this letter is, in some way, to show that one must begin to make calls even if it does not feel quite ready for such an undertaking. The desire and willingness to serve, along with all the theory previously studied, will certainly enable her to initiate this activity.

Keywords: Therapy; Early Training; Technical Support; Emotional Support.

Resumen: El inicio de la práctica clínica en la psicología es vivido por la joven terapeuta como un gran desafío. Envuelve sentimientos de esperanza, de miedo, de incertidumbre, entre otros. Esos sentimientos vienen de la difícil tarea de no saltar etapas en ese proceso, de tener paciencia para obtener información teórica, metodológica y personal, y aún ir más allá de la teoría estudiada, en un espacio en que las respuestas no son tan obvias. Convertirse terapeuta es un camino solitario, en que es necesario también, buscar respuestas en si misma, tanto en los cuestionamientos que surgen en su vida personal como en los relativos a la profesión. La persona que escoge ser terapeuta necesita entender que terapia es una expresión que significa cuidado, tratamiento y cura. Cuidar implica consideración, interés, atención, solicitud, celo, preocupación, actitudes comunes en las terapeutas iniciantes en su relación con los clientes, pero raras cuando se refieren a ellas mismas. Por tanto la joven terapeuta necesita estar disponible para los encuentros, el contacto, condición que se hace imprescindible en la relación terapéutica y, al mismo tiempo, ella debe cuidar de si misma. El objetivo de esta carta es, de alguna forma, mostrar, que la persona necesita comenzar a realizar atendimientos, aunque no se sienta totalmente lista para tal tarea. El deseo y la disposición para atender, además de toda la teoría estudiada, con seguridad, la capacitará para iniciar esa actividad.

Palabras-clave: Terapia; Inicio Profesional; Soporte teórico; Soporte Emocional.

Sempre que me deparo com as angústias, próprias de uma jovem psicoterapeuta, remeto-me a situações muito próximas pelas quais passei e com as quais, de alguma forma, me defronto, vinte anos depois, na posição de uma professora que ensina a difícil tarefa de ser terapeuta, no sentido amplo da palavra. O que me estimula a escrever esta mensagem é esse contato com jovens terapeutas que buscam a compreensão teórica e prática da clínica gestáltica. O objetivo desta carta é escrever algumas palavras raramente ditas nas salas de aulas ou nas supervi- 
sões clínicas e que acredito ser importante ouvir ou ler no início dessa estrada tão teorizada e ao mesmo tempo tão desconhecida.

A primeira coisa que gostaria de dizer a você é que eu a entendo! Entendo o seu sofrimento e a sua esperança, a sua angústia e a sua satisfação na busca para ser uma melhor terapeuta. Estar face a face com uma pessoa que procura ajuda, que sofre, é mesmo um grande desafio. Você pode me perguntar: "Será que eu realmente disponho do conhecimento e da habilidade mínima necessária para atender essa pessoa"? Suas dúvidas e seus sentimentos tocam-me e, por isso, estou aqui hoje, por meio dessa carta, disposta a dividir com você alguns conhecimentos e experiências que talvez possam facilitar um começo de carreira tão repleta de cobranças e incertezas.

As cobranças são de todos e provêm de todas as partes: de seus pais, de seus parentes, de seus amigos, do seu namorado, de seus professores e, muitas vezes, de você mesma. Trata-se de mensagens explícitas, às vezes até mesmo implícitas que, certamente, tornam-se ainda mais pesadas por se misturarem com as suas próprias. Cuidado, essas mensagens provavelmente não são exatamente as mesmas. Você escuta das pessoas: "Você acabou de formar e ainda precisa estudar"? "Você já tem cliente, quantos"? "Você prestou atenção que gasta mais do que ganha?" "Será que essa profissão vale a pena"? Nesse momento, perante o outro, você arruma uma desculpa ou fica muda, mas no seu silêncio podem-se adivinhar algumas inquietações: "Como tem sido difícil, será que estou no caminho certo"? "Quero tanto, será que vou conseguir"? "Preciso passar por tudo isso para ser uma grande terapeuta"? Você sabe o quanto esse caminho é longo e solitário! Essa é a grande diferença da sua cobrança em relação às demais pessoas. Então, afaste-se o máximo que você der conta do que os outros pensam, da cobrança das outras pessoas.

Fico aqui lembrando sua carinha animada e angustiada ao mesmo tempo. Animada, pois você está realizando tudo o que sempre sonhou. Você já se formou, no momento cursa a especialização que escolheu, montou seu consultório, além disso, pode fazer terapia, pode fazer supervisão, está tudo, aparentemente, certo. Ao mesmo tempo você tem medo de não dar conta do recado, de não estar no caminho certo, afinal, ainda faltam o cliente, a segurança no atendimento, a experiência tão sonhada. Falta, acima de tudo, calma, paciência, tolerância ao encarar as cobranças diante das incertezas que a assolam. As incertezas são inúmeras, são teóricas, metodológicas, filosóficas, financeiras, pessoais. Tente passar com seriedade por esse período de seu crescimento, mas jamais se esqueça da serenidade.

Rilke, poeta existencialista, descreve o que é ser artista e hoje repasso esse ensinamento a você, uma terapeuta, profissão tão próxima de uma artista. Ele escreve:
(...) ser artista precisa deixar-se amadurecer como uma árvore, que não apressa sua seiva e permanece confiante durante as tempestades da primavera, sem o temor de que o verão não possa vir depois. Ele vem apesar de tudo. Mas só chega para os pacientes, para os que estão ali como se a eternidade se encontrasse diante deles, com toda a amplidão e serenidade. Aprendo isto diariamente, aprendo em meio a dores às quais sou grato: a paciência é tudo.

Sei o quanto tem sido pesado para você entrar em um mundo muito diferente daquele com que você acostumava lidar. Como é complicado deixar de ser uma grande aluna e se perceber como uma pequena terapeuta. Acabaram-se as notas e você ficou perdida sem elas, pois eram uma excelente bússola. A nota, a partir de agora é tão subjetiva, não é?! Tenho percebido o quanto você tem sido cruel consigo mesma ao avaliar seus atendimentos, quando escuto: "Foi péssimo! Se esse cliente tivesse sido atendido por alguém mais experiente teria sido bem meIhor". Talvez sim, talvez não. Sei apenas que esse caminho autopunitivo não te ajuda. Você precisa alterar sua rota para, assim, chegar o dia em que sua dúvida se converterá de destruidora em sua melhor colaboradora. Essas perguntas a seguir, certamente, serão mais importantes para seu crescimento:

- "Eu tive atitude intencional e consciente de acolhimento da vivência do cliente"?

- Eu busquei compreender o cliente e permiti que ele se desvelasse para mim em sua autenticidade"?

- "Eu acompanhei meu cliente com todo o cuidado"?

- "Eu encontrei meu cliente, mesmo falhando em algumas intervenções técnicas”?

- "Eu me comprometi em responder ao meu cliente, com toda minha inteireza, e de uma forma dialogal”?

- "Eu consegui ajudar o meu cliente a dar um próximo passo?"

\section{Enfim:}

- "A despeito dos referidos erros na condução das sessões, o processo como um todo revelou bons resultados?"

São questões que você deve enfrentar, até porque, somente pela consciência de quem somos e onde estamos, podemos chegar a algum outro lugar. Não é por acaso que Maslow já dizia: "Se não for você, então quem"? A nota, a partir de agora é sua, mas cuidado, uma nota pode ao mesmo tempo, incentivar seu crescimento ou paralisar seus projetos. Então imagine trocar a pergunta: "Estudei tanto... sei tão pouco... devo desistir"? Para essa outra: "Estudei tanto... o que posso fazer com o que sei e com a pessoa que sou?”. 
Nesse momento, você se volta para si mesma. Você pode responder melhor a essa pergunta do que qualquer outra pessoa, do que procurar a resposta em outro lugar. E mais, espere a hora mais tranquila para formular suas respostas, tente ouvir suas próprias perguntas com amor. Não procure agora respostas que você não está preparada para alcançá-las. No momento, viva suas perguntas! Viva-as com a sua delicadeza. Um dia você, gradativamente, sem tanta pressa, conhecerá essas respostas. De nada adianta olhar para o que falta se não se percebe o que se tem.

Após esses breves comentários, gostaria de lembrarlhe o significado da palavra terapia, pois acredito que esse significado seja fundamental para o seu encontro com o cliente. Se você realmente entendê-lo, ficará mais fácil aceitar que não conseguiu suspender seus preconceitos, ou chegar às coisas mesmas - ideal metodológico tão difícil para todos nós. Terapia é uma expressão que significa cuidado, tratamento e cura. O terapeuta cuida ao ajudar o cliente a colocar-se nas melhores condições possíveis naquele momento. Assim, o cliente pode alcançar seu ajustamento criativo, advindo, então, a cura. O encontro que cura só é possível por meio do cuidado, e o terapeuta deve ser um cuidador, já que ele cuida da dor!

Cuidar vai muito além de toda a teoria estudada por você. Cuidar significa consideração, interesse, atenção, solicitude, zelo, preocupação. Ao que me consta, essas são qualidades que não faltam no seu atendimento, no encontro com o seu cliente. O cuidado somente surge quando a existência de alguém tem importância para o outro. Então, pensar a prática clínica tendo como fundamento o cuidado consiste em nos remeter a atitudes que têm relação mais direta com o cuidado na clínica: respeitar o cliente, interessar-se por ele, dar atenção a ele, dedicar-se e ele, tornar-se disponível para participar de seu destino, de suas buscas, de seus sofrimentos e de suas conquistas, enfim, de sua vida. Imagino você me perguntando: "Somente isso ajuda"?!!! Você não imagina o quanto é difícil alcançar essas atitudes embora elas sejam tão naturais em você.

O cuidado que acabo de descrever deveria existir em todo encontro humano, em toda palavra e em todos os outros meios pelos quais o homem entra em contato com um outro homem e pode, assim, nele atuar, pois o cuidado é parte da esfera do inter-humano. Na psicoterapia, há duas pessoas face a face, de algum modo dirigidas uma para a outra, portanto, são pessoas que estão uma com a outra e separadas uma da outra, enfim, é uma co-presença operante e dialogante. Alcançar essa proposta vai além de qualquer teoria e é disso que lhe falo: esteja aberta ao encontro, ao contato, visto que é uma condição que se faz imprescindível na relação terapêutica.

Não se esqueça de que o cuidado forma e, também, deforma a pessoa, o que pode ser percebido em sua própria experiência. Você foi cuidada (formada e deformada) ao receber valores e adequar sua vida de acordo com aquilo que seus pais, professores, igreja, sociedade consideraram certo. Os cuidados formaram-na e, com certeza, deformaram-na, pois exigiram obediência e adequação, em detrimento da sua expressão pessoal. E você, na vontade de ser aceita, submeteu-se a tudo e a todos e se perdeu de você mesma. Cabe agora a você fazer diferente, comece, portanto, a cuidar de você, para assim cuidar melhor do seu cliente, que também foi formado e deformado, e que agora procura ajuda em seu consultório. Você, psicóloga, tem o privilégio de cuidar sem ter que educá-lo ou moldá-lo, mas apenas acompanhá-lo em seu desvelar. Do contrário, você se comportará como todos os outros que cuidam dele, sem resultado satisfatório.

Para finalizar gostaria de dizer-lhe mais algumas palavras, cara aluna e supervisionanda, uma jovem e competente terapeuta, mas que acredita que a teoria estudada até então é insuficiente para o atendimento clínico e está, no momento, paralisada. Você precisa começar a atender e da melhor forma possível. Entregue-se a esse atendimento, do seu jeito e do seu tamanho, você! Vá ao encontro de seu cliente, encontre-o como e onde você e ele estão, com toda sua inexperiência e vontade. Não importa como, atenda-o! Escute a sua queixa, investigue-a, sem se preocupar se você realmente está fazendo uma redução fenomenológica. Seja curiosa! Pergunte o que for preciso para entender um pouco mais aquilo que o cliente está lhe apresentando. Sua vontade e disposição para atender, além de toda a teoria estudada, com certeza, a capacitará para começar o atendimento.

Quantas vezes, no encontro com o cliente, sua teoria, imprescindível, não é suficiente. O cliente, mais que de um teórico, precisa de uma pessoa, precisa de você, uma pessoa íntegra, disponível, presente, permissiva, companheira, cuidadora! Quantas vezes, por mais elaborado que seja um recurso terapêutico, ele não é satisfatório. E mesmo na hora, em que se esgotam todos os recursos terapêuticos, ainda resta você. No momento em que dois seres humanos permanecem em relação, os conhecimentos teóricos, filosóficos ou metodológicos tornam-se tão irrelevantes! E sabemos que esses são os momentos transformadores.

Quando falo de um comprometimento humano na terapia, não significa, em absoluto, que descarto o comprometimento teórico. Apenas realço que a integração de seu comprometimento humano, do seu conhecimento e da sua capacidade técnica são os responsáveis pela modificação terapêutica. Afinal, um terapeuta comprometido, estuda, se aperfeiçoa, realiza seu trabalho pessoal, desenvolve recursos relacionais, e, assim, sente-se disponível ao encontro com o outro. Esse desenvolvimento global e permanente do terapeuta, às vezes, é penoso, mesmo se, a longo prazo, provoque uma grande satisfação. Nessa busca, você descobrirá que sua eficácia advém, também, da sua aceitação, da liberdade de poder ser você mesma. 
Quanto mais você se deixar ser como você é, tanto mais fácil será você aceitar-se como uma pessoa irremediavelmente imperfeita e que, com toda a certeza, nem sempre atua como gostaria de atuar. Somente quando você aceitar esse seu lugar você terá a chance de dele sair, não é essa a teoria paradoxal da mudança? Você não pode mudar, não pode se afastar do que você é enquanto não aceitar verdadeiramente quem você é. Nesse momento, a mudança acontecerá quase sem ser percebida.

Outra consequência da aceitação de você mesma é que as relações se tornam mais reais. Não é somente seu cliente que precisa ser aceito. As relações reais têm o caráter apaixonante de serem vitais e significativas. Confie nessa experiência e deixe que ela seja a suprema autoridade. Acompanhe seu mostrar-se! Somente pela experiência você se aproxima da verdade, pois ela tem um caráter pré-reflexivo. Aproximar-se da verdade nunca é prejudicial. Assim, os juízos dos outros, embora devam ser ouvidos, e levados em consideração pelo que são, jamais poderão orientá-la.

Certa vez, ouvi em uma palestra três recomendações muito significativas para mim e gostaria de terminar essa carta repassando-as a você. Elas foram proferidas pelo nosso querido professor e gestalt-terapeuta Ari Rehfeld:

Para terminar, uma recomendação aos pacientes, outra aos nossos alunos e, por último, a todos nós.

Aos pacientes quero citar o antigo rabino Nachman de Braslav que disse: "Nunca pergunte o seu caminho a alguém que o conheça, pois você não poderá se perder".

Aos alunos, um antigo pensador japonês Bashô: "Não siga os antigos, procure o que eles procuraram". E a todos nós, a Mafalda: "A mim coube ser eu!"

\section{Com carinho,}

Celana

Celana Cardoso Andrade - Psicóloga Clínica, especialista em Gestaltterapia pelo Instituto de Treinamento e Pesquisa em Gestalt-terapia de Goiânia (ITGT); Mestre em Psicologia Clínica pela Universidade Católica de Goiás (UCG); Docente na Universidade Federal de Goiás (UFG) e no ITGT. Email: celana@terra.com.br. 